\title{
HRTEM Characterization of Nanoparticles in an ODS Ferritic Steel
}

Luke L. Hsiung*, Michael J. Fluss*, Akihiko Kimura**

*Lawrence Livermore National Laboratory, Physical and Life Sciences Directorate L-352, P.O. Box 808

Livermore, CA

**Institute of Advanced Energy Kyoto University, Gokasho, Uji Kyoto 611-0011, Japan

Crystal and interfacial structures of oxide nanoparticles in a $16 \mathrm{Cr}-4 \mathrm{Al}-2 \mathrm{~W}-0.3 \mathrm{Ti}-0.3 \mathrm{Y}_{2} \mathrm{O}_{3}$ ODS ferritic steel have been examined using high-resolution transmission electron microscopy (HRTEM) techniques. Oxide nanoparticles with a complex-oxide core and an amorphous shell were observed. The crystal structure of complex-oxide core is identified to be mainly monoclinic $\mathrm{Y}_{4} \mathrm{Al}_{2} \mathrm{O}_{9}$ (YAM) oxide compound. Orientation relationships between the oxide and matrix are found to be dependent on the particle size. Large particles $(>20 \mathrm{~nm})$ tend to be incoherent and have a spherical shape, whereas small particles $(<10$ $\mathrm{nm})$ tend to be coherent or semi-coherent and have a faceted interface. HRTEM images of a large $(>20$ $\mathrm{nm})$ and a small $(<10 \mathrm{~nm})$ nanoparticles in K3-ODS steel sample are shown in Figs. 1a and 1b. As can be seen in Fig. 1a, the large nanoparticle tends to be near spherical in shape and is incoherent with the matrix. In addition, one can also distinguish the core region with an appearance of lattice fringes from the outer shell region with a featureless appearance. On the other hand, ledges and facets can be readily seen at the interface between the small nanoparticle and the matrix shown in Fig. 1b, which indicates that the small nanoparticle tends to be coherent or semi-coherent with the matrix. A very thin layer of featureless domain can also be found on the left-hand side of the oxide/matrix interface, which is shown in Fig. 2a. Here, an interfacial structure of the small nanoparticles in Fig. 1b. Facets, ledges, interface dislocations, and thin layer of amorphous domains (marked by red arrows) were readily observed at the interface. An orientation relationship between the $\mathrm{Y}_{4} \mathrm{Al}_{2} \mathrm{O}_{9}$ particle and the matrix can be derived from the FFT image to be $[011]_{\alpha} \|[732]_{\text {YAM. }}$. Figure $2 \mathrm{~b}$ shows a large nanoparticle $(>20 \mathrm{~nm})$ becomes perfectly spherical without a core/shell structure after annealing for 168 hours at $900{ }^{\circ} \mathrm{C}$, which suggests that the core/shell structure of oxide nanoparticles formed in the as-fabricated ODS steels is far from chemical equilibrium. Formation mechanisms of ODS nanoparticles are accordingly proposed based on the HRTEM observations. The formation mechanisms basically include the following three stages: (1) Fragmentation of starting $\mathrm{Y}_{2} \mathrm{O}_{3}$ particles to form finely-dispersed fragments during ball milling; (2) Agglomeration and amorphization of fragments mixed with matrix material to form clusters and agglomerates during ball milling; and (3) Crystallization of the amorphous oxide agglomerates to form oxide nanoparticles with a complex-oxide core and a solute-enriched shell.

Reference

[1] This work was performed under the auspices of the U.S. Department of Energy by Lawrence Livermore National Laboratory under Contract DE-AC52-07NA27344. Work at LLNL was funded by the Laboratory Directed Research and Development Program at LLNL under project tracking code 09-SI003. 

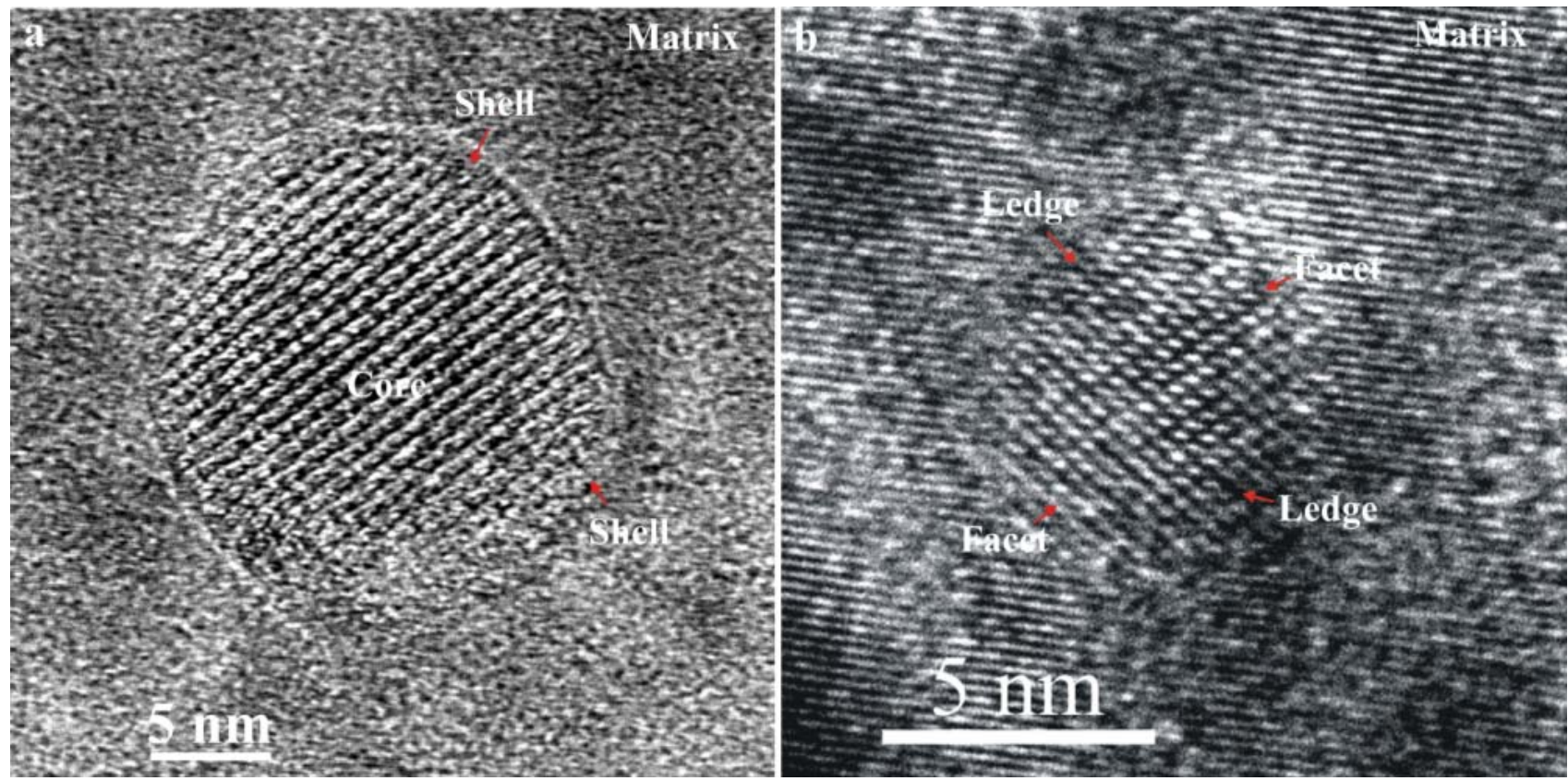

Fig. 1. HRTEM images of (a) a large nanoparticle $(>20 \mathrm{~nm})$ : incoherent interface associated with a core/shell structure and (b) small nanoparticles $(<10 \mathrm{~nm})$ : semi-coherent interfaces associated with facets and ledges.
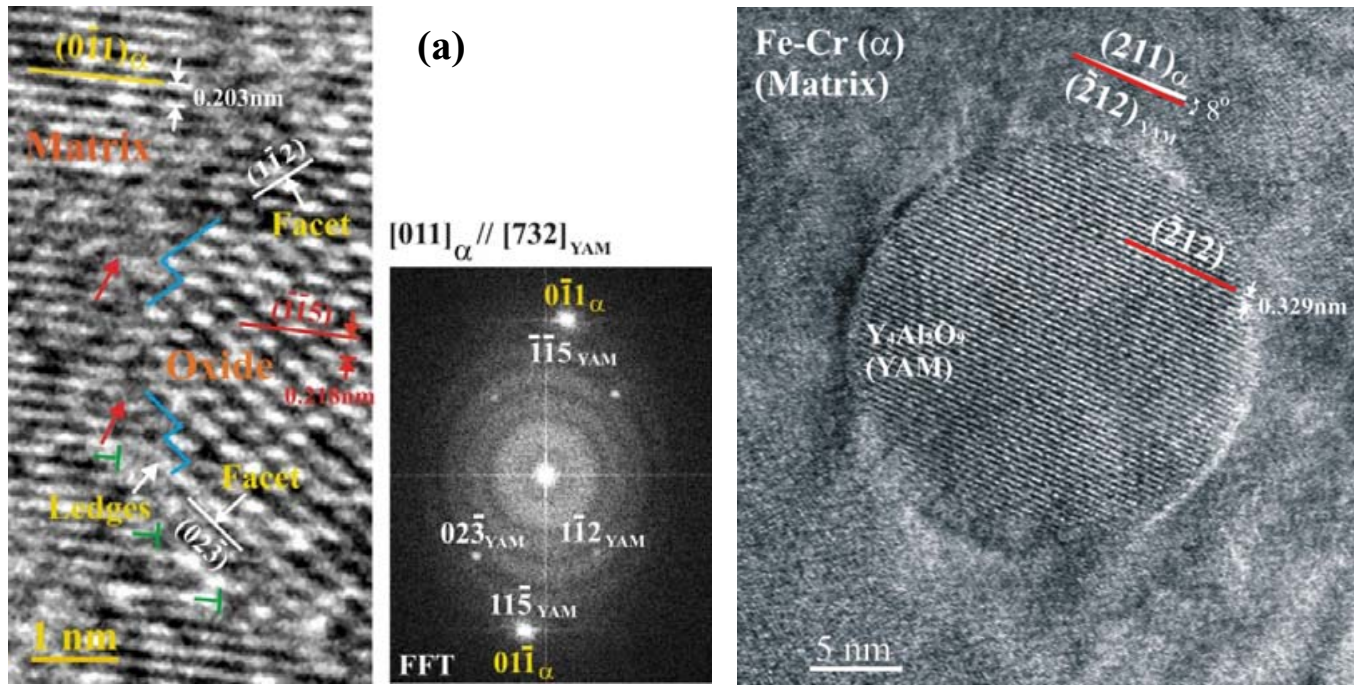

(b)

Fig. 2. (a) HRTEM image shows an interfacial structure between the oxide nanoparticle and the matrix in Fig. 1b. Facets, ledges, dislocations, and thin layer of featureless domains (marked by red arrows) can be readily found at the interfaces. An orientation relationship between the $\mathrm{Y}_{4} \mathrm{Al}_{2} \mathrm{O}_{9}$ oxide and the matrix can be derived from the FFT image. (b) HRTEM image shows a large $\mathrm{Y}_{4} \mathrm{Al}_{2} \mathrm{O}_{9}$ nanoparticle $(>20 \mathrm{~nm})$ becomes perfectly spherical without a core/shell structure after prolonged annealing at $900{ }^{\circ} \mathrm{C}$ for 168 hours. 